\title{
Associates of obesity and weight dissatisfaction among Finnish adolescents
}

\author{
Vera Mikkilä $^{1,2, *}$, Marjaana Lahti-Koski ${ }^{1}$, Pirjo Pietinen ${ }^{1}$, Suvi M Virtanen ${ }^{1,3}$ and \\ Matti Rimpelä ${ }^{4}$ \\ ${ }^{1}$ National Public Health Institute, Mannerheimintie 166, FIN-00300 Helsinki, Finland: ${ }^{2}$ Present address: Division of \\ Nutrition, Department of Applied Chemistry and Microbiology, University of Helsinki, PO Box 27, FIN-00014 \\ University of Helsinki, Finland: ${ }^{3}$ School of Public Health and Medical School, University of Tampere, and Department \\ of Pediatrics, Tampere University Hospital, Tampere, Finland: ${ }^{4}$ National Research and Development Centre for \\ Welfare and Health, Helsinki, Finland
}

Submitted 13 November 2001: Accepted 26 April 2002

\begin{abstract}
Objective: We investigated behavioural and socio-economic factors associated with obesity and weight dissatisfaction among Finnish adolescents.

Design: A total of 60252 Finnish adolescents aged 14 to 16 years filled in a questionnaire about their health, health behaviour and socio-economic background. Food choices were obtained by using a short food-frequency questionnaire. Obesity was defined as a weight at least $120 \%$ of the sex- and height-specific mean weight for subjects.

Results: Of girls and boys, 54\% and 66\%, respectively, were satisfied with their weight. Among dissatisfied normal-weight adolescents, $81 \%$ of girls but only $48 \%$ of boys thought they were overweight. Of obese boys, 25\% were satisfied with their weight. For both genders, obesity and weight dissatisfaction were associated with economic problems in the family. In girls, an association was also found with poor school performance, low educational level of parents and not having evening meals at home; and in boys, with physical inactivity and not eating school lunch. Smoking was more common among girls who were dissatisfied with their weight. Differences in food choices were small between different weight and weight satisfaction categories.

Conclusions: Having normal weight and being satisfied with that weight are favourable for an adolescent. Obesity and weight dissatisfaction are associated mostly with disadvantageous health behaviours and low socio-economic status. Health behaviour seems to be associated more with weight satisfaction than with actual weight.
\end{abstract}

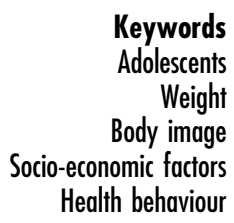

Obesity has become one of the most significant health concerns in developed countries during the last few decades, with the prevalence of obesity increasing among children and adolescents at an alarming rate ${ }^{1-6}$. Although obesity is known to have a genetic background, the rapid increase in prevalence suggests that the primary cause of this global phenomenon lies in lifestyle and environmental changes.

Obesity rarely causes immediate, serious health consequences in childhood or adolescence ${ }^{7}$. However, childhood obesity is associated with many risk factors for cardiovascular diseases, e.g. hyperinsulinaemia, impaired glucose tolerance, dyslipidaemia and hypertension. A disturbing long-term consequence of obesity in childhood and adolescence is that it easily persists into adulthood ${ }^{7}$. Although obesity in adolescence has been shown to be associated with elevated long-term morbidity and mortality, most of the immediate consequences of obesity in childhood and adolescence are psychosocial ${ }^{7}$. People have strong prejudices towards the obese, which may lead to their stigmatisation and discrimination against them in social situations. Obesity in adolescence has been found to be associated with lowered self-esteem ${ }^{8}$.

While the prevalence of overweight is high, the ideal body shape among girls is markedly thin ${ }^{9,10}$. This contradiction may cause distress and lead to unhealthy weight control practices ${ }^{11}$. When setting weight guidelines for adolescents, parents and health professionals may unintentionally reinforce dysfunctional health behaviour in normal-weight adolescents. Dieting has been found to be more associated with weight perception than with actual weight $^{12}$. 
In the present study, with an exceptionally large study population, we investigated weight perceptions and examined these perceptions in relation to the real weight status among Finnish adolescents. Moreover, because of the existing conflict between obesity as a real public health problem and desire for extreme slimness, we aimed to find out the possible risk factors for obesity and weight dissatisfaction. Assuming that they are not two phenomena totally distinct from one another, we were also interested in whether they had common socio-economic and health behavioural determinants.

Thus, the main aim of this study was to describe the complex relationships between weight, weight perceptions and socio-economic and behavioural factors among Finnish adolescents. We find this issue very important, and hope to offer useful information for health education professionals to have a better understanding of the underlying causes and consequences of weight-related problems among adolescents.

\section{Methods}

The subjects consisted of adolescents in the 8th or 9th grade of secondary schools in different parts of Finland, aged 14 to 16 years, who participated in the School Health Promotion Study. The School Health Promotion Study is a collaborative project of the National Research and Development Centre for Welfare and Health, and the Universities of Jyväskylä and Tampere, with the objective of annually assessing the health and health behaviour of Finnish schoolchildren. Participants completed a questionnaire covering questions on their health, health behaviour and socio-economic background. This onehour questionnaire was completed in 1996 or 1997. Nonparticipants were those who were absent from the class. The response rate was $91 \%$ of all students in participating schools. Moreover, 5663 subjects were excluded because they were younger than 14 years or older than 16 years of age, and a further 140 were excluded because they had given obviously unreliable answers (e.g. had chosen option number 1 in all questions). Sixty-seven per cent of the excluded were boys. The final number of subjects was 60252 (30534 girls and 29718 boys).

All information was assessed by the questionnaire. Participants were asked to report their weight in kilograms and their height in centimetres. The body weight category was defined on the basis of internal relative weight, i.e. each person's weight in relation to the mean weight of those of the same sex and height. The relative weight (RW) was expressed as a percentage of the mean weight for sex and height within the sample. Normal weight was defined as relative weight between $80 \%$ and $120 \%$, underweight and obesity as RW $<80 \%$ and RW $>120 \%$, respectively.

Weight perception was assessed by asking 'What do you think about your body weight?', with four options: (1) very overweight; (2) overweight; (3) desirable weight; and (4) underweight or very underweight.

Analyses were carried out in two parts: first, we examined the weight status and weight perception of participants, and, second, we investigated factors independently associated with these. Body weight and weight perceptions were observed both in relation to each other and to other factors, which were classified as follows: (1) socio-economic status (SES) of the family and school performance; (2) exercising, use of alcohol and smoking; and (3) food behaviour.

The socio-economic status of the family was assessed with three questions: the structure of the family, the educational level of the parents, and the economic situation of the family (for options see Table 1). The structure of the family was determined by the question 'Who do you live with?' The economic situation of the family was based on the adolescent's perception of whether their family had economic problems. School performance was assessed by dividing the subjects into tertiles, girls and boys separately, on the basis of the calculated mean value of the marks (this mean value is usually given in school reports in Finland) in their latest school report.

Subjects were divided into four groups according to the frequency of physical exercise. Alcohol consumption was queried in two ways: the frequency of using any amount of alcohol and the number of times being drunk, both questions having three answer options. We constructed a variable by giving $1-3$ points for both questions according to the option chosen. Our variable had three categories: non-user ( 2 points), occasional user ( 3 or 4 points) and regular user ( 5 or 6 points). Smoking habits were assessed with two questions. First the subjects were asked if they smoked or not. Second, if they answered yes, they were asked to report the frequency of smoking.

Food behaviour included questions about school lunch, evening meal at home, and food choices. The latter was described using three factors, which were constructed by Hirvonen et al. ${ }^{13}$ based on the short 15 -item foodfrequency questionnaire. The 'fast food' factor included hamburgers and hot dogs, meat pasties, pizza, soft drinks sweetened with sugar, crisps, chips and sweets. The 'healthy food' factor contained fruits and berries, rye bread, fresh vegetables, salad and yoghurt. The third factor, 'traditional food', included traditional Finnish foods: coffee, sweet buns and sausages. Based on the frequency of items, subjects were divided into tertiles, girls and boys separately.

Independent associations between obesity and weight dissatisfaction and other variables were examined by logistic regression analyses. When using obesity status as the dependent variable, normal weight was used as the reference group and underweight adolescents were excluded. In the analyses concerning weight dissatisfaction, the reference group consisted of those who were 
Table 1 Sociodemographic characteristics of subjects

\begin{tabular}{lcc}
\hline & Girls & Boys \\
& $(n=30534)(\%)$ & $(n=29718)(\%)$ \\
\hline Family & & \\
Two parents & 76.7 & 78.3 \\
One parent and a stepmother/-father & 8.7 & 8.3 \\
One parent & 14.0 & 12.1 \\
Data missing & 0.6 & 1.3 \\
Educational level of family & & \\
Parents without a high school degree & 57.7 & 51.6 \\
Only father has a high school degree & 6.9 & 6.8 \\
Only mother has a high school degree & 13.9 & 15.2 \\
Both have high school degrees & 15.6 & 18.4 \\
Data missing & 5.9 & 8.0 \\
Economic status of family & & \\
Good & 68.6 & 76.7 \\
Some problems & 25.8 & 19.2 \\
Severe problems & 5.0 & 2.8 \\
Data missing & 0.6 & 1.3 \\
School performance & & \\
Highest tertile & 28.1 & 30.0 \\
Middle tertile & 30.5 & 30.4 \\
Lowest tertile & 30.9 & 29.8 \\
Data missing & 10.5 & 9.8 \\
\hline
\end{tabular}

satisfied with their weight and analyses were controlled for the weight category. Odds ratios (ORs) and 95\% confidence intervals (CIs) were computed for obesity status and weight dissatisfaction associated with socioeconomic and behavioural factors.

The SAS statistical package 6.07 was used for analyses ${ }^{14}$. All analyses were carried out separately for girls and boys.

\section{Results}

The majority of participants lived with both parents (Table 1). More than half of the adolescents reported that neither of their parents had a high school degree, and most families had no economic problems. The educational level of the parents as well as the economic situation of the family was better among the boys than among the girls, which suggests that the boys who were absent at the time of the study or who were excluded came from families with lower SES.

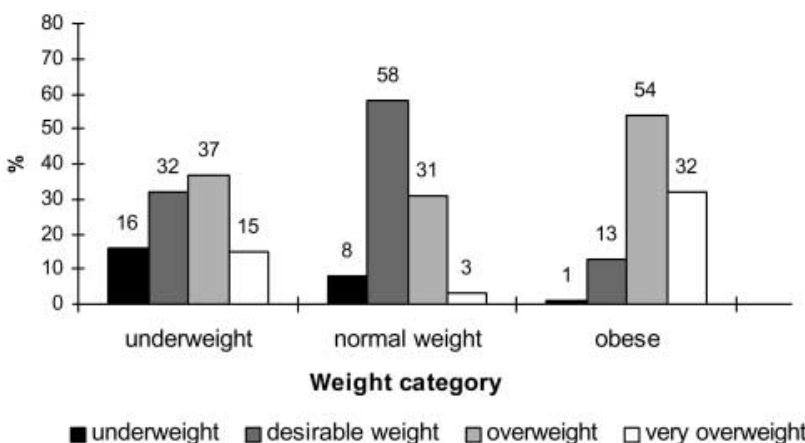

Fig. 1 Weight perception in different weight categories for girls
Regular use of alcohol as well as regular smoking was common in both boys and girls (Table 2). The majority reported eating the school lunch daily, but less than half had evening meals at home with the family.

Weight dissatisfaction was common; $46 \%$ and 34\% of girls and boys, respectively, were dissatisfied with their weight. Moreover, 39\% of girls and 19\% of boys thought that they were overweight. Weight satisfaction was most common among normal-weight adolescents (Figs 1 and 2) and was more than two times more common among the underweight than among the obese. Girls more often considered themselves overweight in all weight categories than boys.

Among those who were normal-weight but dissatisfied with their weight, $81 \%$ of girls but only $48 \%$ of boys thought they were overweight or very overweight. Furthermore, more than half of the underweight girls thought they were overweight. Regarding oneself as overweight was more common among the underweight than among those of

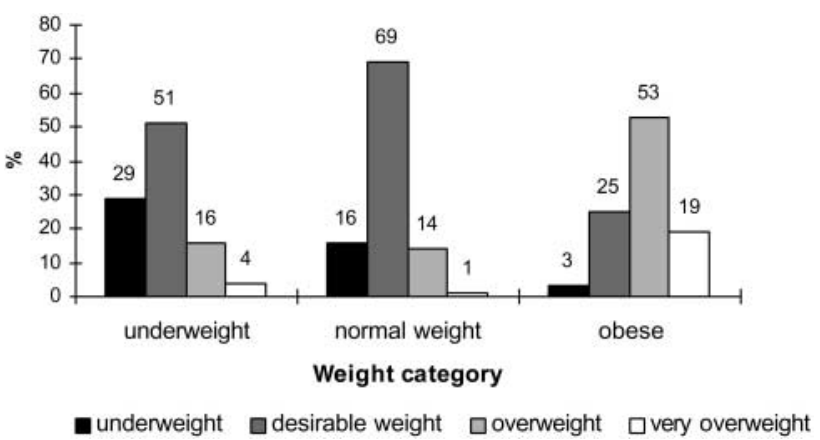

Fig. 2 Weight perception in different weight categories for boys 
Table 2 Health behaviour characteristics of subjects

\begin{tabular}{|c|c|c|}
\hline & $\begin{array}{c}\text { Girls } \\
(n=30534)(\%)\end{array}$ & $\begin{array}{c}\text { Boys } \\
(n=29718)(\%)\end{array}$ \\
\hline \multicolumn{3}{|l|}{ Physical exercise } \\
\hline Less than weekly & 9.1 & 9.0 \\
\hline $1-3$ times a week & 39.5 & 31.2 \\
\hline $4-6$ times a week & 22.1 & 23.2 \\
\hline Daily & 29.2 & 35.4 \\
\hline Data missing & 0.1 & 0.2 \\
\hline \multicolumn{3}{|l|}{ Use of alcohol } \\
\hline Non-user & 25.4 & 29.5 \\
\hline Occasional user & 46.3 & 41.1 \\
\hline Regular user & 26.4 & 27.1 \\
\hline Data missing & 1.9 & 2.3 \\
\hline \multicolumn{3}{|l|}{ Smoking } \\
\hline Non-smoker & 45.3 & 48.3 \\
\hline Ex- or occasional smoker & 29.9 & 26.1 \\
\hline Regular smoker & 24.4 & 23.7 \\
\hline Data missing & 1.4 & 1.9 \\
\hline \multicolumn{3}{|l|}{ School lunch } \\
\hline School lunch daily & 74.8 & 83.1 \\
\hline Takes only bread, milk and/or salad & 18.7 & 10.4 \\
\hline Does not eat the school lunch & 6.3 & 6.2 \\
\hline Data missing & 0.2 & 0.3 \\
\hline \multicolumn{3}{|l|}{ Evening meal at home } \\
\hline Daily with the family & 38.5 & 45.3 \\
\hline Daily without the family & 43.9 & 41.8 \\
\hline No evening meal & 17.4 & 12.6 \\
\hline Data missing & 0.2 & 0.3 \\
\hline \multicolumn{3}{|l|}{ Use of fast food ${ }^{*}$} \\
\hline Highest tertile & 37.6 & 28.9 \\
\hline Middle tertile & 27.3 & 36.0 \\
\hline Lowest tertile & 33.5 & 32.9 \\
\hline Data missing & 1.6 & 2.2 \\
\hline \multicolumn{3}{|l|}{ Use of healthy food $\dagger$} \\
\hline Highest tertile & 33.5 & 32.8 \\
\hline Middle tertile & 32.6 & 32.5 \\
\hline Lowest tertile & 32.8 & 33.4 \\
\hline Data missing & 1.1 & 1.3 \\
\hline \multicolumn{3}{|l|}{ Use of traditional food $\ddagger$} \\
\hline Highest tertile & 34.0 & 34.5 \\
\hline Middle tertile & 31.6 & 31.5 \\
\hline Lowest tertile & 33.5 & 32.2 \\
\hline Data missing & 0.9 & 1.8 \\
\hline
\end{tabular}

*Hamburgers, hot dogs, meat pasties, pizza, soft drinks sweetened with sugar, crisps, chips and sweets. $\dagger$ Fruits and berries, rye bread, fresh vegetables, salad and yoghurt.

$\ddagger$ Coffee, sweet buns and sausages.

normal weight in both girls and boys. Of obese boys, $25 \%$ stated their weight was desirable.

The significant independent risk factors associated with obesity are presented in Table 3. Obesity was strongly associated with low SES of the family, both in girls and boys. Compared with the lowest educational level, significantly fewer of those whose parents belonged to the highest educational group were obese. Having economic problems in the family was also associated with a higher frequency of obesity. Good school performance was inversely associated with being obese in both girls and boys.

The boys who were most active physically were less likely to be obese, compared with inactive boys (Table 3 ).
Among girls, those who used alcohol regularly were more rarely obese than the others (Table 3). Other associations between health behaviour and obesity status were not statistically significant after controlling for all variables. The associations between obesity status and food behaviour tended to be weak. However, girls who did not have evening meals at home were more likely to be obese than were the others. In boys, skipping school lunch was associated with obesity. Obese girls and boys reported eating less fast food than did the others (Table 3).

Weight dissatisfaction was strongly associated with SES of the family and school performance of the respondent, especially among girls (Table 4). High economic status of the family was associated with better weight satisfaction in 
Table 3 Factors associated with obesity status in a multivariate model. Odds ratio (95\% confidence interval) adjusted for all variables

\begin{tabular}{|c|c|c|}
\hline & Girls & Boys \\
\hline \multicolumn{3}{|l|}{ Educational level of family } \\
\hline Parents without a high school degree & 1.00 & 1.00 \\
\hline Only father has a high school degree & $0.62(0.50-0.77)$ & $0.80(0.70-0.96)$ \\
\hline Only mother has a high school degree & $0.82(0.71-0.94)$ & $0.81(0.71-0.92)$ \\
\hline Both have high school degrees & $0.62(0.54-0.73)$ & $0.56(0.48-0.65)$ \\
\hline \multicolumn{3}{|l|}{ Economic status of family } \\
\hline Good & 1.00 & 1.00 \\
\hline Some problems & $1.14(1.03-1.27)$ & $0.95(0.85-1.07)$ \\
\hline Severe problems & $1.41(1.16-1.72)$ & $1.36(1.07-1.72)$ \\
\hline \multicolumn{3}{|l|}{ School performance } \\
\hline Lowest tertile & 1.00 & 1.00 \\
\hline Middle tertile & $0.77(0.69-0.86)$ & $0.79(0.71-0.89)$ \\
\hline Highest tertile & $0.62(0.55-0.70)$ & $0.68(0.61-0.77)$ \\
\hline \multicolumn{3}{|l|}{ Physical exercise } \\
\hline Less than weekly & & 1.00 \\
\hline $1-3$ times a week & \# & $0.84(0.72-0.97)$ \\
\hline $4-6$ times a week & & $0.60(0.51-0.71)$ \\
\hline Daily & & $0.54(0.46-0.62)$ \\
\hline \multicolumn{3}{|l|}{ Use of alcohol } \\
\hline Non-user & 1.00 & \\
\hline Occasional user & $0.86(0.77-0.96)$ & \# \\
\hline Regular user & $0.63(0.55-0.73)$ & \\
\hline \multicolumn{3}{|l|}{ School lunch } \\
\hline School lunch daily & & 1.00 \\
\hline Takes only bread, milk and/or salad & \# & $0.82(0.70-0.96)$ \\
\hline Does not eat the school lunch & & $1.20(1.01-1.43)$ \\
\hline \multicolumn{3}{|l|}{ Evening meals at home } \\
\hline Daily with the family & 1.00 & \\
\hline Daily without the family & $0.96(0.86-1.06)$ & \# \\
\hline No evening meal & $1.24(1.09-1.41)$ & \\
\hline \multicolumn{3}{|l|}{ Use of fast food* } \\
\hline Lowest tertile & 1.00 & 1.00 \\
\hline Middle tertile & $0.83(0.74-0.92)$ & $0.77(0.69-0.86)$ \\
\hline Highest tertile & $0.60(0.53-0.67)$ & $0.62(0.55-0.69)$ \\
\hline
\end{tabular}

\# - No significant association found and therefore excluded from final multivariate model.

${ }^{*}$ Hamburgers, hot dogs, meat pasties, pizza, soft drinks sweetened with sugar, crisps, chips and sweets.

both girls and boys. High educational level of the parents, good school performance and non-smoking were also associated with weight satisfaction in girls but not in boys. Physically inactive boys were more often dissatisfied with their weight than active boys.

Food behaviour had stronger associations with weight satisfaction than with actual weight. In both girls and boys, those who did not eat school lunch and those who did not have evening meals at home were more likely dissatisfied with their weight than the others. Furthermore, those reporting the least use of fast food were more often dissatisfied with their weight as compared with those in the highest tertile of fast food use.

As expected, body weight category was strongly associated with weight satisfaction. Those of normal weight were most likely satisfied with their weight. Controlling for body weight had only a minor effect on the odds ratios of the other factors in the model, i.e. although many of the dissatisfied were obese, the actual weight did not explain all of the associations of weight dissatisfaction among the subjects.

\section{Discussion}

Weight dissatisfaction was common and weight perceptions were often unrealistic. Gender differences in weight perceptions were considerable. Both obesity and weight dissatisfaction were most common among adolescents from families with low socio-economic status. Health behaviour had stronger associations with weight perception than with actual weight.

Although the study population consisted of a large number of subjects, it was not a randomised sample of all adolescents in Finland. Every borough in Finland was invited to take part in the study and participation was voluntary. However, if a borough decided to participate, the study was carried out in every secondary school in the borough. The final sample represents well areas of 
Table 4 Factors associated with weight dissatisfaction in a multivariate model, controlled for actual weight category. Odds ratio (95\% confidence interval) adjusted for all variables

\begin{tabular}{|c|c|c|}
\hline & Girls & Boys \\
\hline $\begin{array}{l}\text { Weight category } \\
\text { Underweight } \\
\text { Normal weight } \\
\text { Obese }\end{array}$ & $\begin{array}{l}2.91(2.62-3.24) \\
1.00 \\
9.39(8.15-10.82)\end{array}$ & $\begin{array}{l}2.06(1.84-2.31) \\
1.00 \\
6.81(6.13-7.56)\end{array}$ \\
\hline $\begin{array}{l}\text { Educational level of parents } \\
\text { Parents without a high school degree } \\
\text { Only father has a high school degree } \\
\text { Only mother has a high school degree } \\
\text { Both have high school degrees }\end{array}$ & $\begin{array}{l}1.00 \\
0.88(0.80-0.98) \\
0.90(0.83-0.96) \\
0.87(0.81-0.93)\end{array}$ & \# \\
\hline $\begin{array}{l}\text { Economic status of family } \\
\text { Good } \\
\text { Some problems } \\
\text { Severe problems }\end{array}$ & $\begin{array}{l}1.00 \\
1.34(1.26-1.42) \\
1.54(1.37-1.73)\end{array}$ & $\begin{array}{l}1.00 \\
1.38(1.30-1.47) \\
1.83(1.58-2.12)\end{array}$ \\
\hline $\begin{array}{l}\text { School performance } \\
\text { Lowest tertile } \\
\text { Middle tertile } \\
\text { Highest tertile }\end{array}$ & $\begin{array}{l}1.00 \\
0.87(0.82-0.93) \\
0.77(0.72-0.83)\end{array}$ & \# \\
\hline $\begin{array}{l}\text { Physical exercise } \\
\text { Less than weekly } \\
1-3 \text { times a week } \\
4-6 \text { times a week } \\
\text { Daily }\end{array}$ & $\#$ & $\begin{array}{l}1.00 \\
0.88(0.78-0.96) \\
0.72(0.65-0.79) \\
0.67(0.61-0.73)\end{array}$ \\
\hline $\begin{array}{l}\text { Smoking } \\
\text { Non-smoker } \\
\text { Ex- or occasional smoker } \\
\text { Regular smoker }\end{array}$ & $\begin{array}{l}1.00 \\
1.26(1.19-1.34) \\
1.28(1.19-1.37)\end{array}$ & \# \\
\hline $\begin{array}{l}\text { School lunch } \\
\text { School lunch daily } \\
\text { Takes only bread, milk and/or salad } \\
\text { Does not eat the school lunch }\end{array}$ & $\begin{array}{l}1.00 \\
1.28(1.20-1.36) \\
1.67(1.50-1.86)\end{array}$ & $\begin{array}{l}1.00 \\
1.15(1.02-1.21) \\
1.24(1.13-1.38)\end{array}$ \\
\hline $\begin{array}{l}\text { Evening meal at home } \\
\text { Daily with the family } \\
\text { Daily without the family } \\
\text { No evening meal }\end{array}$ & $\begin{array}{l}1.00 \\
1.08(1.02-1.14) \\
1.36(1.27-1.47)\end{array}$ & $\begin{array}{l}1.00 \\
1.09(1.03-1.15) \\
1.22(1.12-1.31)\end{array}$ \\
\hline $\begin{array}{l}\text { Use of fast food* } \\
\text { Lowest tertile } \\
\text { Middle tertile } \\
\text { Highest tertile }\end{array}$ & $\begin{array}{l}1.00 \\
0.97(0.91-1.04) \\
0.88(0.83-0.94)\end{array}$ & $\begin{array}{l}1.00 \\
0.90(0.85-0.96) \\
0.93(0.82-0.97)\end{array}$ \\
\hline $\begin{array}{l}\text { Use of healthy food } \dagger \\
\text { Lowest tertile } \\
\text { Middle tertile } \\
\text { Highest tertile }\end{array}$ & $\#$ & $\begin{array}{l}1.00 \\
0.96(0.91-1.03) \\
0.86(0.81-0.91)\end{array}$ \\
\hline
\end{tabular}

different size and sociodemographic structure. Those students who were absent from the class at the time of the study may have been different from those who were present. Our two exclusion criteria (age, unreliability of answers) both resulted in more boys than girls being excluded. The differences between the answers of girls and boys (different family structure and educational level of parents) suggest that the boys not present or excluded may have been from families with low SES. The reader should, nevertheless, keep in mind that the gender differences in SES might partly be due to the possible gender differences in reporting. However, as the sample size was quite large and the response rate was high, the results can be generalised to same-aged adolescents across the country.

Defining overweight or obesity in children and adolescents is difficult ${ }^{15}$. The criteria used for adults are not suitable, and no uniform and generally accepted definition of obesity exists for children and adolescents ${ }^{15}$. At this age, the variations in body weight may not always reflect body fat content because body composition varies with the degree of maturation. Cole et al. proposed the use of body mass index (BMI), and developed certain age- and sex-specific cut-off points to help international 
comparisons between prevalence rates of obesity in children $^{15}$. However, since our aim was not to report prevalence but to find differences within a very large study population, we were able to use an internal definition of relative weight and a strict cut-off point to identify obese adolescents with high specificity. Our definition does not allow us to draw any conclusions about the overall prevalence of overweight or obesity among Finnish adolescents. Moreover, because the weight class was defined on the basis of relative weight, not on the real body composition, it is possible that some of the adolescents classified as obese may in fact have been muscular rather than obese.

Weight and height were self-reported, which presumably led to misclassification of some extent in dividing subjects into three weight categories. An underestimation of reported weight by subjects would lead to an underestimation of the mean weight at each height, and may have therefore resulted in classifying some underweight adolescents as normal-weight, and some normalweight as overweight.

A self-administered questionnaire has some methodological limitations. Self-reported information may lead to misclassification of weight status and should be used with caution when reporting the prevalence of obesity in a population ${ }^{16}$. However, self-reported data can be used to understand adolescent obesity and its correlates ${ }^{17,18}$. As regards the associations found in this study, the degree and effects of the possible reporting bias are very difficult to estimate. The reader should, nevertheless, always keep in mind that some of the results might partly be explained by inaccurate information given by subjects.

Adolescents in industrialised countries are interested in their weight, and Finns are no exception. In a recent study among Finnish adolescents $79 \%$ of the girls and $44 \%$ of the boys were dissatisfied with their body shape ${ }^{19}$. The results of studies investigating weight satisfaction and weight perceptions among adolescents are quite consistent: weight dissatisfaction is common, especially among girls, with most dissatisfied girls thinking that they are too fat, while boys equally often see themselves as too thin as too fat $^{9,12,19-23}$. Weight perceptions have frequently been found to be unrealistic ${ }^{9,12,19,20,24}$. The finding in our study that regarding oneself as overweight was more prevalent among the underweight than among those of normal weight suggests that underweight adolescents may often have distorted body image.

Adulthood obesity is most common in low socioeconomic groups ${ }^{25}$. Based on cross-sectional studies, however, it is impossible to draw any conclusions about causality or its direction. Low SES of the family has also been shown to be associated with childhood obesity ${ }^{3,26}$. Adolescents from low socio-economic groups in our study were also more likely to be obese. An even stronger association was found between poor school performance and obesity status. Adolescents were in either the 8th or 9th grade of secondary school. School performance during these two years has a great influence on the upcoming possibilities in choosing between senior high schools and vocational schools, and, thus, may well predict the adolescents' own SES in the future.

Associations between weight dissatisfaction and SES were very similar to associations between obesity status and SES, although the weight dissatisfaction analysis was controlled for weight category, i.e. the higher prevalence of weight dissatisfaction found in lower SES groups is independent of the higher prevalence of obesity in these groups. The results of earlier studies are contradictory ${ }^{23,27,28}$. The variable results may partly depend on different study designs, but they also indicate that the issue is culture-dependent, therefore making it difficult to compare studies carried out in different societies.

Physically active boys were more rarely obese or dissatisfied with their weight than their less active counterparts, whereas no similar association was found among girls. One could expect that the adolescents who wished to lose or gain weight would exercise more to achieve this. Our results do not support this assumption. Obese girls reported drinking less than other girls, supporting the finding of a previous study ${ }^{29}$. This somewhat unexpected result may partly be explained by underreporting. The association between weight dissatisfaction and frequent smoking found among girls in our study has also been observed earlier ${ }^{19,21,30}$. In a study carried out in the United States, 39\% of the girls who smoked frequently stated that they smoked to control their weight $^{31}$.

Consistent with other studies ${ }^{12,32}$, food behaviour seemed to have stronger associations with weight satisfaction than with actual body weight. Not having evening meals at home was associated with obesity status in girls and with weight dissatisfaction in both sexes. Obese boys as well as the girls and boys who were dissatisfied with their weight reported eating school lunch less frequently than the others. This may suggest that the obese try to lose weight by skipping meals. An inverse association between meal frequency and weight has been reported previously ${ }^{33}$.

Obese girls and boys reported consuming fast food less frequently than did their slimmer peers. Weight satisfaction was associated with eating fast food among both sexes, and among boys also with eating healthy foods. The obese and those wanting to be thinner may, however, more often underreport the use of fast food. The negative labelling of 'junk food', thought to be unhealthy and fattening, may lead to both underreporting of its use and avoiding it in reality. In numerous studies, weight dissatisfaction has been found to have strong associations with problems related to eating and food, healthcompromising ways of weight control, and even eating disorders ${ }^{12,21,22,34,35}$.

Overall, having normal weight and being satisfied with 
that weight are favourable for an adolescent. Obesity status and weight dissatisfaction, regardless of the direction of dissatisfaction, are associated mostly with disadvantageous health behaviours and low SES. Weight dissatisfaction seems to be very common in Finland, as it is in most Westernised countries. Weight perceptions are often unrealistic; girls, in particular, tend to consider themselves as fat even when they are not, which may lead to unhealthy weight control practices such as skipping meals or smoking. At the same time, a large proportion of obese boys are satisfied with their weight, thus being at risk of developing social and health-related problems.

\section{References}

1 Flegal KM. The obesity epidemic in children and adults: current evidence and research issues. Med. Sci. Sports Exerc. 1999; 31: S509-14.

2 Reilly JJ, Dorosty AR. Epidemic of obesity in UK children. Lancet 1999; 354: 1874-5.

3 Kromeyer-Hauschild K, Zellner K, Jaeger U, et al. Prevalence of overweight and obesity among school children in Jena (Germany). Int. J. Obes. 1999; 23: 1143-50.

4 Thomsen BL, Ekstrom CT, Sorensen TI. Development of the obesity epidemic in Denmark: cohort, time and age effects among boys born 1930-1975. Int. J. Obes. 1999; 23: $693-701$.

5 Moreno LA, Sarría A, Fleta J, et al. Trends in body mass index and overweight prevalence among children and adolescents in the region of Aragón (Spain) from 1985 to 1995. Int. J. Obes. 2000; 24: 925-31.

6 Flegal KM, Troiano RP. Changes in the distribution of body mass index of adults and children in the US population. Int. J. Obes. 2000; 24: 807-18.

7 Must A, Strauss RS. Risks and consequences of childhood and adolescent obesity. Int. J. Obes. 1999; 23(Suppl.2): S2-11.

8 Strauss RS. Childhood obesity and self-esteem. Pediatrics 2000; 105: 111-9.

9 Guaraldi GP, Orlandi E, Boselli P, et al. Body image assessed by a video distortion technique: the relationship between ideal and perceived body image and body dissatisfaction. Eur. Eat. Disord. Rev. 1999; 7: 121-8.

10 Parkinson KN, Tovée MJ, Cohen-Tovée EM. Body shape perceptions of preadolescent and young adolescent children. Eur. Eat. Disord. Rev. 1998; 6: 126-35.

11 Neumark-Sztainer D, Story M, Resnick MD, et al. Lessons learned about adolescent nutrition from the Minnesota Adolescent Health Survey. J. Am. Diet. Assoc. 1998; 98: $1449-56$

12 Strauss RS. Self-reported weight status and dieting in a crosssectional sample of young adolescents: National Health and Nutrition Examination Survey III. Arch. Pediat. Adolesc. Med. 1999; 153: 741-7.

13 Hirvonen T, Lahti-Koski M, Roos E, et al. Food choices and school lunch eating among adolescents [in Finnish, English summary]. Sosiaalilääketieteellinen Aikakauslebti [J. Soc. Med.] 1999; 36: 162-71.

14 SAS Institute, Inc., SAS/STAT User's Guide, Version 6, 4th ed. Vol. 2. Cary, NC: SAS Institute, Inc., 1989.

15 Cole T, Bellizzi M, Flegal KM, et al. Establishing a standard definition for child overweight and obesity worldwide: international survey. Br. Med.J. 2000; 320: 1240.

16 Crawley HF, Portides G. Self-reported versus measured height, weight and body mass index amongst 16-17 year old British teenagers. Int.J. Obes. Relat. Metab. Disord. 1995; 19: 579-84.

17 Davis H, Gergen PJ. The weights and heights of MexicanAmerican adolescents: the accuracy of self-reports. Am. J. Public Health 1994; 84: 459-62.

18 Goodman E, Hinden BR, Khandelwal S. Accuracy of teen and parental reports of obesity and body mass index. Pediatrics 2000; 106: 52-8.

19 Koskelainen M, Sourander A, Helenius H. Dieting and weight concerns among Finnish adolescents. Nord. J. Psychiat. 2001; 55: 427-31.

20 Ryan YM, Gibney MJ, Flynn MA. The pursuit of thinness: a study of Dublin schoolgirls aged 15 y. Int. J. Obes. 1998; 22: 485-7.

21 Moore D. Body image and eating behavior in adolescents. J. Am. Coll. Nutr. 1993; 12: 505-10.

22 Fisher M, Schneider M, Pegler C, et al. Eating attitudes, health-risk behaviors, self-esteem and anxiety among adolescent females in a suburban high school. J. Adolesc. Health 1991; 12: 377-84.

23 Wardle J, Marsland L. Adolescent concerns about weight and eating: a social-development perspective. J. Psychosom. Res. 1990; 34: 377-91.

24 Furnham A, Calnan A. Eating disturbance, self-esteem, reasons for exercising and body weight dissatisfaction in adolescent males. Eur. Eat. Disord. Rev. 1998; 6: 58-72.

25 Lahti-Koski M, Vartiainen E, Männistö S, et al. Age, education and occupation as determinants of trends in body mass index among adults in Finland from 1982 to 1997. Int.J. Obes. 2000; 24: 1669-76.

26 Spiegelare M, Dramaix M, Hennart P. The influence of socioeconomic status on the incidence and evolution of obesity during early adolescence. Int. J. Obes. 1998; 22: 268-74.

27 Story M, French S, Resnick M, et al. Ethnic/racial and socioeconomic differences in dieting behaviors and body image perceptions in adolescents. Int. J. Eat. Disord. 1995; 18: $173-9$.

28 Ogden J, Thomas D. The role of familial values in understanding the impact of social class on weight concern. Int. J. Eat. Disord. 1999; 25: 273-9.

29 Neumark-Sztainer D, Story M, French SA, et al. Psychosocial concerns and health-compromising behaviors among overweight and nonoverweight adolescents. Obes. Res. 1997; 5: 237-49.

30 Crisp AH, Stavrakaki C, Halek C, et al. Smoking and pursuit of thinness in schoolgirls in London and Ottawa. Postgrad. Med.J. 1998; 74: 473-9.

31 Camp DE, Klesges RC, Relyea G. The relationship between body weight concerns and adolescent smoking. Health Psychol. 1993; 12: 24-32.

32 Davis C, Durnin JV, Gurevich M, et al. Body composition correlates of weight dissatisfaction and dietary restraint in young women. Appetite 1993; 20: 197-207.

33 Bellisle F, McDevitt R, Prentice AM. Meal frequency and energy balance. Br. J. Nutr. 1997; 77: S57-70.

34 French SA, Story M, Downes B, et al. Frequent dieting among adolescents: psychosocial and health behavior correlates. Am. J. Public Health 1995; 85: 695-701.

35 Wichström L. Social, psychological and physical correlates of eating problems. A study of the general adolescent population in Norway. Psychol. Med. 1995; 25: 567-579. 